\title{
Surgery of Giant Aneurysm
}

\author{
Petra Wahjoepramono \\ and Eka J. Wahjoepramono
}

\subsection{Sign and Symptoms}

Aneurysm bigger than $25 \mathrm{~mm}$ is called giant aneurysm [1], further subdivided by morphology into saccular, fusiform, or dolichoectatic aneurysms [2]. Epidemiologically, they are very rare, comprising only $0.5 \%$ of all intracranial aneurysms, while others describe it as $3-5 \%$ of all intracranial aneurysms $[1,3,4]$; the epidemiology of intracranial aneurysms among the general population amounts to $0.2-9.9 \%$ [5]. In pediatric patients, the incidence of giant aneurysms and aneurysms of the posterior circulation is greater than those in adult patients [6]. The most common type is the saccular giant aneurysm, accounting for $98 \%$ of cases [7]. Fusiform types are more commonly found in the posterior circulation and MCA [1]. These lesions have a female preponderance and are diagnosed mostly between 40 and 60 years of age [2]. These lesions are found

\footnotetext{
P. Wahjoepramono

Department of Neurosurgery, Medical Faculty of Universitas Padjadjaran, Hasan Sadikin Hospital, Bandung, West Java, Indonesia
}

Department of Neurosurgery, Faculty of Medicine Universitas Pelita Harapan (UPH), Neuroscience Centre Siloam Hospital Lippo Village,

Tangerang, Indonesia

E. J. Wahjoepramono $(\bowtie)$

Department of Neurosurgery, Faculty of Medicine Universitas Pelita Harapan (UPH), Neuroscience Centre Siloam Hospital Lippo Village,

Tangerang, Indonesia most often in the anterior circulation, affecting the ICA, MCA, and ACA [1, 2], while in the posterior circulation, they most commonly occur at the basilar artery, vertebrobasilar junction, PCA, and PICA [2]. Multiple giant aneurysms can be found in $7 \%$ of patients [2].

The most common presenting symptoms for these lesions are mass effect complaints, seizures caused by irritated neural tissue, or compression of cranial nerves [2, 4], which are very different from the subarachnoid bleed usually found in smaller aneurysms [2, 4]. Additionally, the occurrence of thrombus formation in these aneurysms may produce symptoms of thromboembolic event in the parent vessel or perforator vessels [2]. Thromboembolism may occur in up to $60 \%$ of giant aneurysms, and its probability increases along with aneurysm size. Hydrocephalus had been reported due to the compression of giant aneurysms near the cerebral aqueduct, and carotid-cavernous fistulae (CCF) can result from ruptured aneurysms of the ICA cavernous segment [2].

\subsection{Investigation}

These aneurysms must be thoroughly investigated as to its vascular anatomy, such as the presence of perforators, the size and orientation of the aneurysm neck, and its distal outflow (Fig. 20.1). Giant aneurysms frequently display calcification, 

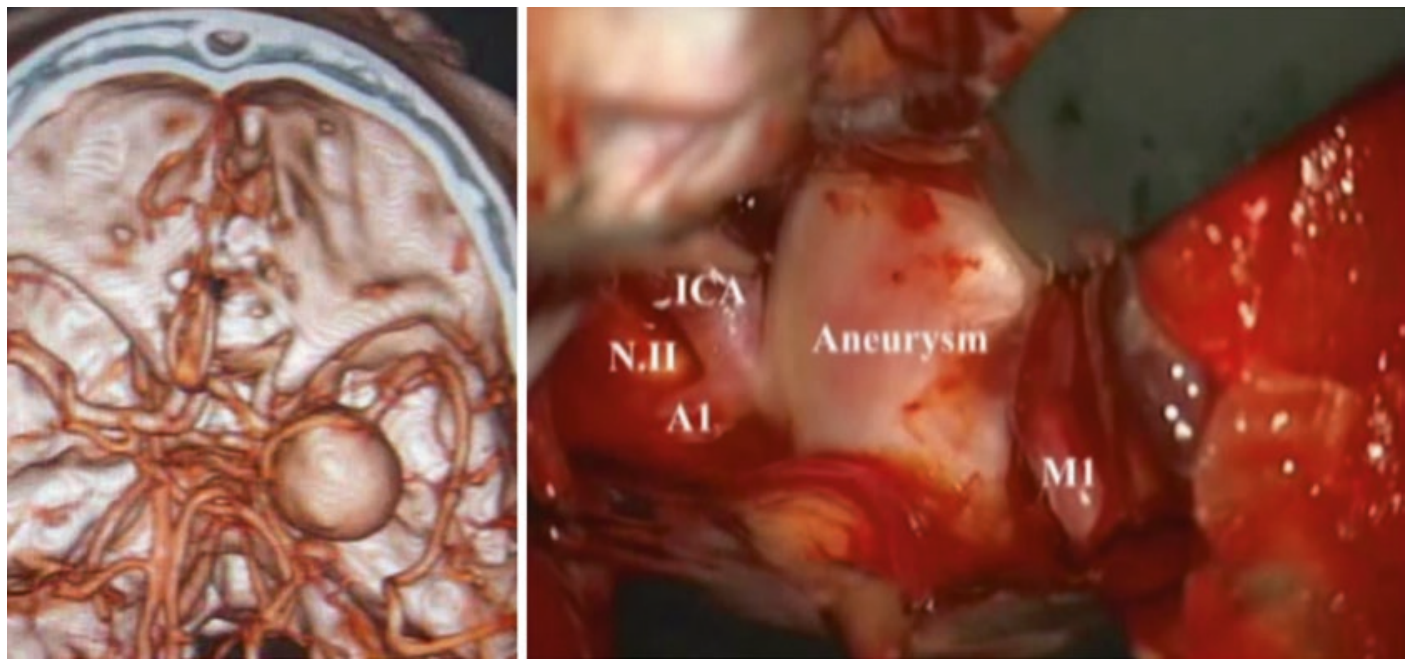

Fig. 20.1 Left: Three-dimensional CT scan of a 50-year-old, female with left M1 giant aneurysm. Right: Intraoperative finding after a wide sylvian fissure dissection

thrombosis, and wall thickening around the neck, while there may be multiple perforator vessels present from the parent artery or even from the aneurysmal sac in the case of fusiform aneurysms [4]. The gold standard diagnostic procedure would be digital subtraction angiography (DSA), which provides the best picture of cerebrovascular anatomy and provides information about the suitability for vessel bypass. DSA can be combined with CT angiography to provide information about surrounding bony anatomy for surgical approach and monitor the presence of calcified thrombus. CT scan is very useful in evaluating for calcification [1], and MRI may be performed if there is a suspected ischemic event, to investigate peritumoral edema and to evaluate intraluminal thrombus [1]. Preoperative assessment of these patients includes balloon occlusion tests during angiography, if the surgeon plans to sacrifice the ipsilateral ICA [2]. Intraoperatively, patients may be monitored using electroencephalography (EEG) to detect any changes in the electrical activity, as well as continuous transcranial Doppler (CTD) to check the cerebral blood flow [2].

The natural course of giant unruptured aneurysm has been previously reported by Wiebers et al. [8]; in anterior circulation the 5-year cumulative risk is about $40 \%$, while in the posterior circu- lation including posterior communicating artery, the risk is about $50 \%$. A study by ISUIA (International Study of Unruptured Intracranial Aneurysms) group shows the rupture rate at $6 \%$ in the first year after diagnosis alone [5, 9], with a more recent study by the UCAS Japan investigators reporting a rupture risk of giant aneurysms at $76.26 \%$ within 3 years [3], with aneurysms at the posterior and anterior communicating arteries being more likely to rupture $[3,5,9]$. The mortality rate of such ruptures reaches $20-70 \%$ [10, 11], reaching higher than $60 \%$ within 2 years of diagnosis [12]. It is therefore established that such rupture rates were similar or worse to the risks taken when a similar lesion is treated, either through surgery or endovascular treatment. More recent studies on the natural course of aneurysms have not found any other parameters indicative of rupture risk [13].

\subsection{Steps of Surgery}

\subsubsection{Surgical Approach}

Microsurgical clipping has the advantage of being able to relieve mass effect associated with nerve compression, especially in aneurysms with thrombus formation or atheroma [14]. 
The main principles of giant aneurysm surgery are to prepare the proximal and distal control, avoid the blunt dissection, and appreciate all the perforators, and to achieve circumferential dissection of the aneurysm might be very difficult [12]. The goals of surgical management of giant aneurysms are:

1. To isolate the aneurysm from the blood circulation

2. To preserve cerebral blood flow distal to the aneurysm

3. To relieve mass effect on neural structures caused by the aneurysm $[1,2,15]$.

Several microsurgical techniques which are used in the management of giant aneurysms include: microsurgical clipping, bypass of parent artery (ICA) using saphenous vein graft or the MCA, temporary ligation of the ICA to help clipping, aneurysm wrapping with muscle or fascia, or combined microsurgical and endovascular treatment [2].

Microsurgical clipping of giant aneurysms can be performed, because all aneurysms must have a "neck." [4] With the use of fenestrated clips, aneurysms with large necks can undergo vessel reconstruction to create an aneurysm neck [4] (Fig. 20.2).
The presence of perianeurysmal edema, which is most often found in the MCA circulation, may complicate the microsurgical clipping [16].

There are several approaches available for microsurgery of giant aneurysms of the carotid artery or the basilar tip; an approach through the middle fossa is recommended. The important surgical anatomy in this region is the cavernous sinus, which includes several natural corridors available to access this region, usually divided into the ten triangular spaces [2]. Skeletonization of the ICA in the carotid canal through Glasscock's triangle [12] is performed to treat intracavernous aneurysms [2]. Orbito-zygomatic approach is used to maximize exposure [12].

Certain location of the posterior circulation aneurysm could be approach through subtemporal such as the upper basilar artery segment [2]. The transpetrosal approach or far-lateral approach may be used for lower lesions [12, 17].

To reduce mass effect of the giant aneurysm after clipping is performed, the aneurysm dome can be directly punctured to exsanguinate the sac when no thrombus is present and perform suction decompression [4, 12] (Fig. 20.3). If there is thrombus, calcification or atheroma is present, thrombectomy may be performed on the aneurysm sac, also called endoaneurysmectomy [4].
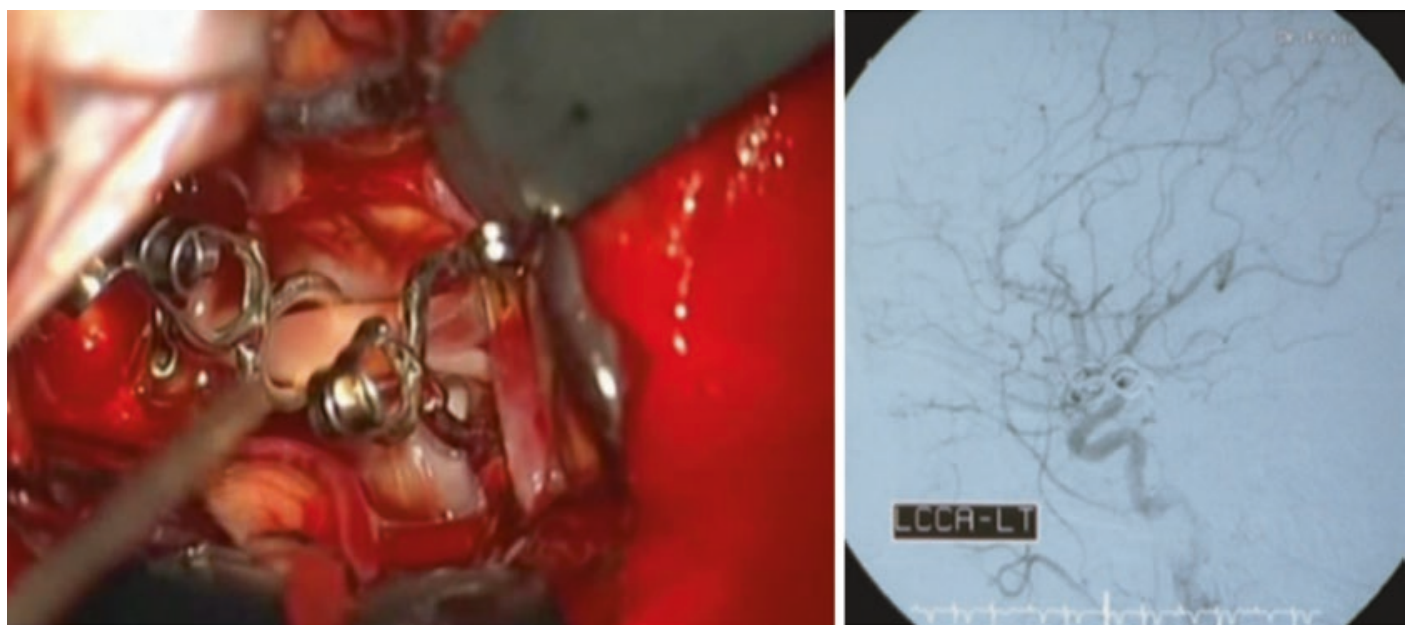

Fig. 20.2 Left: Same case of Fig. 20.1 shows intraoperative view of giant aneurysm undergoing vessel reconstruction with multiple fenestrated clips. Right: Angiography confirmation of MCA flow 


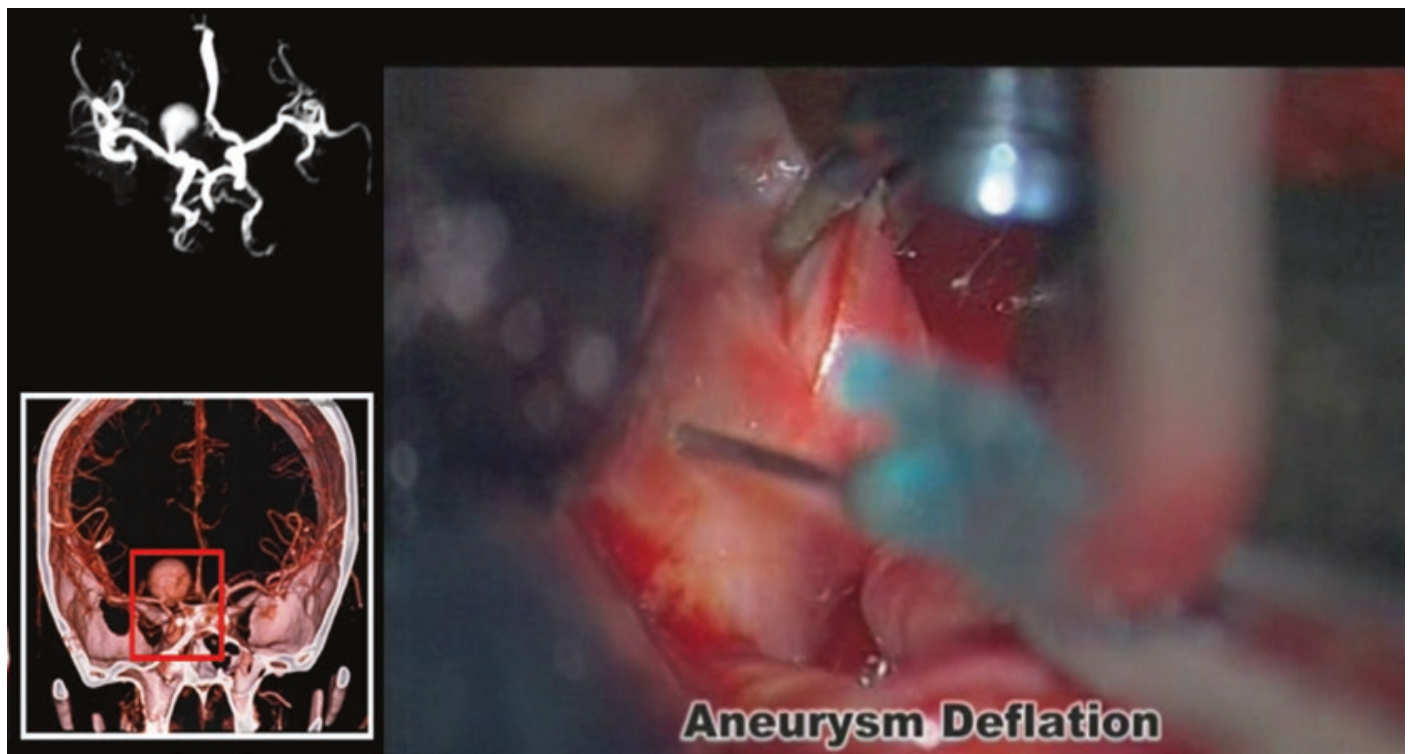

Fig. 20.3 Aneurysm deflation using the wing needle no 25G

Aneurysm repair using wrapping or clip wrapping with the muscle or fascia can be used to maximize outcomes in ruptured aneurysms [12]. Aneurysms which are broad-based, frail, or complex may also be clipped using augmented "cotton-clipping" technique [18]. This technique can also be used to perform emergency repair in the case of ruptured aneurysm.

Low-flow and high-flow bypass techniques have been used to provide revascularization of the distal circulation in the treatment of giant aneurysms [4]. Vessel reconstruction using clips also serve the same function, which is to guarantee CBF distal to the aneurysm [4].

Microsurgical treatment may be advantageous in comparison with endovascular treatment in cases of complex basilar artery aneurysms. Performing surgical clipping of the aneurysm may provide selective occlusion of the basilar artery aneurysm while avoiding damage to the thalamoperforators which may adhere to the posterior aspect of the aneurysm, compared to endovascular treatment where visualization of the perforators cannot be achieved, and the risk of brainstem damage due to ischemia is greater [19].

Adjunctive techniques which can be used in giant aneurysm surgery include deep hypothermic circulatory arrest (DHCA) $[4,20,21]$ and the use of excimer laser-assisted nonocclusive anastomosis (ELANA) bypass [22, 23]. DHCA may be performed to temporarily reduce blood flow to the aneurysm, facilitating the surgeon to perform surgical clipping and neck reconstruction. However, it has several drawbacks, including unpredictable recovery after circulatory arrest and possibility of postoperative brain hemorrhage [24]. A study by Ponce et al. also shows significant mortality and morbidity rates for using DHCA, even though most patients had improved neurological function after surgery [21]. Neuroprotective agents may also be used to improve outcome after surgery, especially if DHCA will be used. Barbiturates are traditionally used to reduce cerebral blood volume and metabolism before the ischemic procedure [12].

The ELANA technique enables surgeons to perform a high-flow bypass without utilizing temporary clips, which makes it a reasonable alternative to other methods of direct revascularization, such as direct anastomosis [23]. The elimination of temporary clips from the procedure provides the surgeon with longer safe operating time without cerebral ischemia and eliminates the need of exposing the proximal parent artery before the procedure, which is especially beneficial in the posterior fossa [23]. 


\subsubsection{Endovascular Approach}

Endovascular management has the advantage of decreased morbidity, due to its nonsurgical nature [25]; aneurysms at the posterior circulation especially show higher morbidity after microsurgery [26]. The endovascular management of giant aneurysms can be performed as long as the aneurysm does not show signs of intraluminal thrombus; if there is thrombus, then endovascular management will not be able to relieve the mass effect caused by the aneurysm itself, even though it could occlude the aneurysm from the circulation.

The endovascular management for giant aneurysms are [25]:

1. The parent artery could be occluded by using coils or balloons.

2. Coiling of the aneurysm coiling of the aneurysm and spare the parent artery.

3. Balloon-, stent-, or neck-bridging-assisted device for selective coiling [27].

4. Selective occlusion with ethylene vinyl alcohol copolymer (ONYX).

5. Sacrifice the parent artery after bypass surgery.

Parent vessel occlusion is a very simple technique which is guaranteed to exclude the aneurysm from cerebral circulation [4, 25]. This is the endovascular treatment of choice if the patient can tolerate parent vessel occlusion [25]. Multiple tests must be done before this treatment, using balloon occlusion test, to ensure that the cerebral circulation is not compromised by blocking the parent artery [25]. A study by Linskey et al. demonstrated that even without previous BOT, up to $75 \%$ of patients can tolerate ICA occlusion [28]. The vertebral artery, however, can be safely occluded, except where the patient only has a single vertebral artery without a patent PCoA [25].

Selective occlusion of giant aneurysms, whether using coils or ONYX embolization device, emphasizes on filling the aneurysm lumen and occluding the aneurysm from the circulation as thrombus forms within the lumen [25]. As most giant aneurysms are formed with large necks, coil-assisted devices such as stents, balloons, or flow diverters are often used [25]. The re-endothelialization of the parent artery after such a procedure is key to preserving a patent lumen and reducing reopening of the aneurysm [29].

Another treatment option is to use flowdiverting stents [4]. These devices have more metal coverage and lower porosity in comparison with standard intracranial stents and have the capability of creating blood flow inside their artificial lumen and induce thrombus formation in the dome of giant aneurysms as blood flow into the dome decreases. These stents are also capable of providing a scaffold for neointimal growth in the vessel. The role of flow diverters against giant aneurysms is effective, with permanent major complication occurring in $3 \%$ of patients in a study by Piano et al. [30] and 5-10\% of patients in other studies [31]. Previous studies have documented encouraging results when these stents are used against aneurysms of the anterior circulation $[32,33]$, defined as aneurysms from the ICA below the anterior choroidal artery. However, they are not as effective against aneurysms in the vertebrobasilar system [34]. It is thought that the vertebrobasilar system with its many perforators are not suitable for flow-diverting stents, as these stents also occlude the perforators, in some cases up to 2 years after stent placement [34]. The resulting ischemia of the pons may lead to unacceptable morbidity [34]. These devices may also be used in conjunction with coils to achieve complete occlusion of the aneurysm [35].

The main concern about selective occlusion is that the embolization device may disengage over time, either by coil become compaction, the coil sometimes migrate, degeneration of the thrombus intraluminal or migration of the ONYX clot into the parent artery $[25,26,36]$. This problem is caused by the inherent nature of giant aneurysms, with their large lumen volume, which sometimes cannot be adequately packed with these devices $[25,26]$. Stable occlusion of these aneurysms requires at least $25 \%$ packing of its volume, which is difficult to achieve with large-volume aneurysms [25]. In a study by van Rooij et al. [25], it is found that nearly all giant aneurysms show reopening after endovascular treatment in 
the 6-month postoperative period, even up to several years of stable condition. The follow-up strategy for these patients is to schedule additional coiling procedures along with routine follow-up, with decreased patient compliance as a result [25, 37]. MRA has also been suggested as a routine follow-up procedure after endovascular treatment [37].

\subsection{Expert Opinion/Suggestion to Avoid Complication}

In several cases such as paraclinoid giant aneurysms, combined approach using microsurgical and endovascular management can be performed [38]. Paraclinoid giant aneurysms are often atherosclerotic and calcified, difficult exposure and dissection of the aneurysm dome, and difficulty in exposure and proximal control through temporary clipping [38, 39]. In such cases, temporary occlusion of the parent artery can be achieved through the endovascular method, while microsurgery is used to expose and clip the tumor, followed with suction decompression of the aneurysm dome [4]. Flow alteration using a combined microsurgical and endovascular method may be used to treat fusiform basilar artery aneurysms [40]. Sughrue et al. [18] championed a combined approach using microsurgery and endovascular therapy as an adjunct in the treatment of giant aneurysms.

\section{References}

1. Hanel RA, Spetzler RF. Surgical treatment of complex intracranial aneurysms. Neurosurgery. 2008;62(6):11.

2. Aguiar PH, Zicarelli CA, Isolan G, Antunes AC. Giant brain aneurysms of anterior circulation. Surgical anatomy. Revista Chilena de Neurocirugía. 2013;39:6.

3. Investigators TUJ. The natural course of unruptured cerebral aneurysms in a Japanese cohort. N Engl J Med. 2012;366(26):9.

4. Sekhar LN, Tariq F, Mai JC, Kim LJ, Ghodke B, Hallam DK, et al. Unyielding progress: treatment paradigms for giant aneurysms. Clin Neurosurg. 2012;59:16.

5. Investigators TISOUIA. Unruptured intracranial aneurysms - risk of rupture and risks of surgical intervention. N Engl J Med. 1998;339(24):8.
6. Mehrotra A, Nair AP, Das KK, Srivastava A, Sahu RN, Kumar R. Clinical and radiological profiles and outcomes in pediatric patients with intracranial aneurysms. J Neurosurg Pediatr. 2012;10:7.

7. Yasargil M. Microneurosurgery. New York: Georg Thieme Verlag; 1994.

8. Wiebers D, Whisnant J, Huston J, Meissner I, Brown RJ, Piepgras D, et al. Unruptured intracranial aneurysms: natural history, clinical outcome, and risks of surgical and endovascular treatment. Lancet. 2003;12(362):7.

9. Investigators ISoUA. Unruptured intracranial aneurysms - risk of rupture and risks of surgical intervention. N Engl J Med. 1998;3339:8.

10. Barrow DL, Alleyne C. Natural history of giant intracranial aneurysms and indications for intervention. Clin Neurosurg. 1995;42:30.

11. Orz Y, Kobayashi S, Osawa M, Tanaka Y. Aneurysm size: a prognostic factor for rupture. Br J Neurosurg. 1997;11:5.

12. Ramachandran M, Retarekar R, Raghavan ML, Berkowitz B, Dickerhoff B, Correa $\mathrm{T}$, et al. Assessment of image-derived risk factors for natural course of unruptured cerebral aneurysms. J Neurosurg. 2016;124:7.

13. Komotar RJ, Mocco J, Solomon RA. Guidelines for the surgical treatment of unruptured intracranial aneurysms. The 1st annual J Lawrence Pool Memorial Research Symposium, New York; 2008. p. 39.

14. Dengler J, Maldaner N, Bijlenga P, Burkhardt J-K, Graewe A, Guhl S, et al. Perianeurysmal edema in giant intracranial aneurysms in relation to aneurysm location, size, and partial thrombosis. J Neurosurg. 2015;123:7.

15. Rodríguez-Hernández A, Lawton MT. Anatomical triangles defining surgical routes to posterior inferior cerebellar artery aneurysms. J Neurosurg. 2011; 114:7.

16. Safavi-Abbasi S, Moron F, Sun H, Oppenlander ME, Kalani MYS, Mulholland CB, et al. Techniques and long-term outcomes of cotton-clipping and cottonaugmentation strategies for management of cerebral aneurysms. J Neurosurg. 2016;125:720.

17. Kellner CP, Haque RM, Meyers PM, Lavine SD, Connolly ES Jr, Solomon RA. Complex basilar artery aneurysms treated using surgical basilar occlusion: a modern case series. J Neurosurg. 2011;115:9.

18. Sughrue ME, Saloner D, Rayz VL, Lawton MT. Giant intracranial aneurysms: evolution of management in a contemporary surgical series. Neurosurgery. 2011;69(6):10.

19. Wait SD, Killory BD, Nakaji P, Zabramski JM. Cardiac standstill for cerebral aneurysms in 103 patients: an update on the experience at the Barrow Neurological Institute. J Neurosurg. 2011; 114:8.

20. van Doormaal T, van der Zwan A, Verweij B, Regli L, Tulleken C. Giant aneurysm clipping under protection of an excimer laser-assisted non-occlusive anastomosis bypass. Neurosurgery. 2010;66(3):8. 
21. Langer DJ, Vajkoczy P. ELANA: excimer laserassisted nonocclusive anastomosis for extracranial-tointracranial and intracranial-to-intracranial bypass: a review. Skull Base. 2005;15(3):15.

22. Khandelwal P, Kato Y, Sano H, Yoneda M, Kanno T. Treatment of ruptured intracranial aneurysms: our approach. Minim Invasive Neurosurg. 2005;48(6):4.

23. Rooij WJ, Sluzewski M. Endovascular treatment of large and giant aneurysms. Am J Neuroradiol. 2009;30:6.

24. Sluzewski M, Menovsky T, Rooij WJ, Wijnalda D. Coiling of very large or giant cerebral aneurysms: long-term clinical and serial angiographic results. Am J Neuroradiol. 2003;24:5.

25. Aguilar-Perez M, Kurre W, Fischer S, Bazner H, Henkes H. Coil occlusion of wide-neck bifurcation aneurysms assisted by a novel intra- to extraaneurysmatic neck-bridging device (pCONus): initial experience. Am J Neuroradiol. 2014;35:965.

26. Linskey ME, Jungreis CA, Yonas H Jr, Hirsch WL, Sekhar LN, Horton JA, et al. Stroke risk after abrupt internal carotid artery sacrifice: accuracy of preoperative assessment with balloon test occlusion and stable xenon-enhanced CT. Am J Neuroradiol. 1994;15:15.

27. Niemela M, Koivisto T, Kivipelto L, Ishii K, Rinne J, Ronkainen A, et al. Microsurgical clipping of cerebral aneurysms after the ISAT study. Acta Neurochir. 2005;94:3.

28. Piano M, Valvassori L, Quilici L, Pero G, Boccardi E. Midterm and long-term follow-up of cerebral aneurysms treated with flow diverter devices: a singlecenter experience. J Neurosurg. 2013;118:9.

29. Wong GKC, Kwan MCL, Ng RYT, Yu SCH, Poon WS. Flow diverters for treatment of intracranial aneurysms: current status and ongoing. Clin Trials. 2011;18(6):4.

30. Lylyk P, Miranda C, Ceratto R, Ferrario A, Scrivano $\mathrm{E}$, Luna $\mathrm{H}$, et al. Curative endovascular reconstruction of cerebral aneurysms with the pipeline embolization device: the Buenos Aires experience. Neurosurgery. 2009;64(4): 10 .

31. Nelson PK, Lylyk P, Szikora I, Wetzel S, Wanke I, Fiorella D. The pipeline embolization device for the intracranial treatment of aneurysms trial. Am J Radiol. 2011;32(1):7.
32. Siddiqui AH, Abla AA, Kan P, Dumont TM, Jahshan S, Britz GW, et al. Panacea or problem: flow diverters in the treatment of symptomatic large or giant fusiform vertebrobasilar aneurysms. J Neurosurg. 2012;116:8.

33. Nossek E, Chalif DJ, Chakraborty S, Lombardo K, Black KS, Setton A. Concurrent use of the pipeline embolization device and coils for intracranial aneurysms: technique, safety, and efficacy. J Neurosurg. 2015;122:8.

34. Voormolen MH, Plazier M, Parizel P, Ridder DD, Maas AIR, Hernesniemi JA. Microsurgical removal of Onyx HD-500 from an aneurysm for relief of brainstem compression. J Neurosurg. 2010;113:3.

35. Plowman RS, Clarke A, Clarke M, Byrne JV. Sixteenyear single-surgeon experience with coil embolization for ruptured intracranial aneurysms: recurrence rates and incidence of late rebleeding. J Neurosurg. 2011;114:12.

36. Arnautović K, Al-Mefty O. Angtuaco E. A combined microsurgical skull-base and endovascular approach to giant and large paraclinoid aneurysms. Surg Neurol. 1998;50(6):14.

37. Ota $\mathrm{T}$. The treatment of large and giant paraclinoid internal carotid artery aneurysms. J Vascu Med Surg. 2013;1(2):2.

38. Hoh BL, Putman CM, Budzik RF, Carter BS, Ogilvy CS. Combined surgical and endovascular techniques of flow alteration to treat fusiform and complex wide-necked intracranial aneurysms that are unsuitable for clipping or coil embolization. J Neurosurg. 2001;95:12.

39. Roloff C, Berg P, Bendicks C, Zähringer K, Janiga G, Thévenin D. Flow investigation inside a cerebral giant aneurysm. 17th international symposium on applications of laser techniques to fluid mechanics, July 7-10 2014, Lisbon, Portugal; 2014.

40. Molyneux AJ, Kerr RS, Yu L-M, Clarke M, Sneade $\mathrm{M}$, Yarnold JA, et al. International subarachnoid aneurysm trial (ISAT) of neurosurgical clipping versus endovascular coiling in 2143 patients with ruptured intracranial aneurysms: a randomised comparison of effects on survival, dependency, seizures, rebleeding, subgroups, and aneurysm occlusion. Lancet. 2005;366:8.

Open Access This chapter is licensed under the terms of the Creative Commons Attribution 4.0 International License (http://creativecommons.org/licenses/by/4.0/), which permits use, sharing, adaptation, distribution and reproduction in any medium or format, as long as you give appropriate credit to the original author(s) and the source, provide a link to the Creative Commons license and indicate if changes were made.

The images or other third party material in this chapter are included in the chapter's Creative Commons license, unless indicated otherwise in a credit line to the material. If material is not included in the chapter's Creative Commons license and your intended use is not permitted by statutory regulation or exceeds the permitted use, you will need to obtain permission directly from the copyright holder. 